\title{
Splenic Angiosarcoma
}

National Cancer Institute

\section{Source}

National Cancer Institute. Splenic Angiosarcoma. NCI Thesaurus. Code C4564.

A malignant vascular neoplasm arising from the spleen. 